3. Батищев Д. И. Методы оптимального проектирования : Учеб. пособие для вузов. М. : Радио и связь, 1984. 248 с.

4. Великанов К.М. Расчёты экономической эффективности новой техники: Справочник. Л. : Машиностроение, 1990. 448 с.

DOI https://doi.org/10.30525/978-9934-588-79-2-1.40

NATURAL-LIKE TECHNOLOGIES OF PROTECTION OF RADIO-ELECTRONIC EQUIPMENT FROM THE IMPACT OF POWERFUL ELECTROMAGNETIC RADIATIONS

\author{
Iasechko M. M. \\ Doctor of Technical Sciences, \\ Associate Professor at the Department of Air Defense Armaments \\ of the Land Forces \\ Ivan Kozhedub Kharkiv National Air Force University \\ Piskunov S. \\ Candidate of Technical Sciences, Associate Professor, \\ Head of the Department of Air Defense Armaments of the Land Forces \\ Ivan Kozhedub Kharkiv National Air Force University

\section{Voinov V.} \\ Candidate of Technical Sciences, \\ Senior Lecturer at the Department of Air Defense Armaments \\ of the Land Forces \\ Ivan Kozhedub Kharkiv National Air Force University \\ Kharkiv, Ukraine
}

Development, creation and use of generators with a radiation power of the order of and more than $1 \mathrm{GW}$ with pulse duration of $10^{-9}$ to $10^{-15} \mathrm{sec}-$ onds necessitates the further development of methods and devices for the protection of radio electronic means. This is due to the possibility of both accidental and deliberate (as a result of terrorist acts) use of such generators, which can lead to the REM disruption at considerable distances. At the same time, the threat of REM serviceability disruption is usually created when electromagnetic radiation (EMR) interacts with antennas, communication lines, conductors and radioelements of equipment. This interaction 
leads to the transformation of the electromagnetic field into voltages and currents.

The most vulnerable to the EMR influence are the REM elements directly connected to the antenna output, to the cables and conductors. In addition to these elements, the cables themselves are exposed to impulse voltages, which in certain cases can damage their insulation and cause a short circuit between its cores and the sheath. The most dangerous in terms of its impact on radio electronic equipment (REE) is a powerful EMR of the ultrashort pulse duration (UPD) [1-6].

Proceeding from this, the problem of ensuring the durability and reliability of modern REM to the impact of powerful EMR of ultrashort pulse duration acquires a pronounced systemic character.

REE features, as a protection object, determine the requirements for the applied protective devices, which must:

- have high speed;

- not influence the characteristics of the protected radio facilities;

- have stability of characteristics in a wide range of temperatures under the action of damaging EMR factors;

- have ability to quickly restore its electrical strength in conditions of multiple exposure to EMR;

- have overall dimensions and weight smaller than the overall dimensions and mass of the protected equipment.

An analysis of the capabilities of the methods and means of protection developed to date has shown that they do not fully meet the requirements for the REM protection.

Thus, despite a wide range of ongoing research in the development of effective methods and the creation of means for REM protection from the impact of a powerful EMR, there is no protection technology. In turn, the protection technology should provide a unified methodological position for solving the problem of reducing the level of electromagnetic field intensity affecting the REM. The solution of the existing problem is proposed on the basis of the complex application of plasma protection technologies using gaseous and modified solid-state media.

The aim of the work: assessment of the possibility of using plasma media for complex REM protection from the impact of a powerful pulsed EMR.

1. The case of a gaseous plasma medium. The dependence of the logarithm of the ratio of electron densities to the pulse amplitude for different pulse durations, obtained using (1), is shown in Fig. 1 


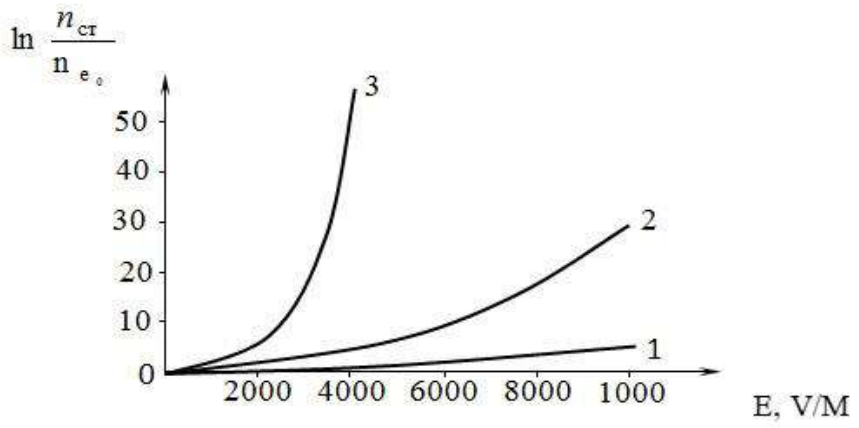

Fig. 1. Dependence of the logarithm of the ratio of the electron density to the electric field strength for times: $1-0.01 ; 2-0.1$;

$3-1$ in fractions of the pulse duration $\tau_{p}=3 \mathrm{~ns}$

It is established that the breakdown intensity of the electric field depends on the initial concentration of electrons in the discharge volume and the EMR duration. When the ratio of the critical concentration to the initial concentration is changed only by a factor of 5 and the air pressure is $750 \mathrm{~mm} \mathrm{Hg}$, the breakdown strength of the field decreases from $30 \mathrm{kV} / \mathrm{m}$ to $20 \mathrm{kV} / \mathrm{m}$. With an increase in the pulse duration by an order of magnitude, the breakdown field strength is reduced by a factor of $5 \lg n_{c r} / n_{e 0}=20$. As the EMR duration is increased by a factor of 10 , the breakdown strength of the electric field decreases by a factor of 3 .

2. The case of a solid-state plasma medium. The dependence of the EMR damping $\gamma / \omega$ on the non-equilibrium parameter is shown in Fig. 2.

In accordance with (3) for the intensity of the radioisotope source of $70 \mu \mathrm{Cu} / \mathrm{cm}^{2}$, due to the non-equilibrium properties of solid-state plasma, the EMR damping coefficient can reach values of the order of $70 \mathrm{~dB}$. 


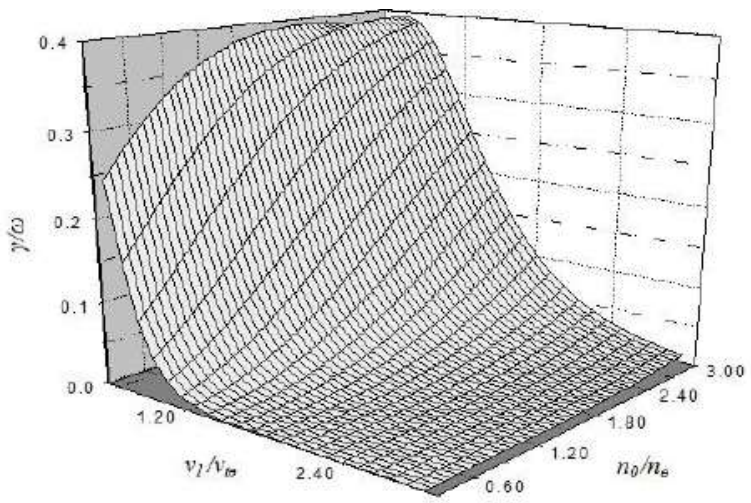

\section{Fig. 2. Dependence of EMR damping on the non-equilibrium parameter of solid-state plasma}

1. The performed theoretical evaluations testify to the principle possibility of using the proposed technologies for creation of means for REM protection from the EMR influence. The choice of the required initial electron concentration in the gaseous plasma leads to a decrease in the breakdown field strength. Consequently, when creating the necessary initial electron concentration inside the waveguide or between the walls of the case and the cable braiding, a real possibility of REM protection from the impact of powerful EMR appears.

2. The use of a solid-state plasma medium as a shielding material by selecting the intensity of the radioisotope source, as well as the number of layers of the dielectric matrix, allows controlling the absorbing properties of the material. The promising nature of the proposed technology lies in the possibility of its integrated use to protect against possible penetration channels, with limitations on the weight dimensions of protection devices.

\section{References:}

1. Iasechko M., Tymochko O., Shapran Y., Trofymenko I., Maksiuta D., Sytnyk Y. Loss definition of charged particles in the discharge gap of the opening of the box-screens during the formation of a highly conductive channel. IJATCSE. 2019. № 8 (1.3). Pp. 1-9.

2. Iasechko M., Larin V., Maksiuta D., Ochkurenko O., Samsonov Y., Lyashenko H., Zinchenko A. Influence of ionization source onto macroscopic parameters of the air media in the holes in cops-screensof radio 
electronic means. APRN Journal of Engineering and Applied Sciences. 2019. № 14 (20). Pp. 3566-3571.

3. Iasechko M., Turinskyi O., Burdin M., Larin V., Gnusov Y., Ikaev D., Borysenko V., Manoylo V. Protection of board radioelectronic equipment from the destructive powerful electromagnetic radiation with the use of natural technologies. IJETER. 2019. № 7 (11). Pp. 542-548.

4. Iasechko M., Sotnikov O., Syrotenko A., Larin V., Iasechko S., Ochkurenko O., Volkov A. Model of Combined Solid Plasma Material for the Protection of Radio-Electronic Means of Optical and Radio Radiation. IJATCSE. 2019. № 8 (4). Pp. 1241-1247.

5. Iasechko M., Sotnikov O., Larin V., Ochkurenko O., Maksiuta D. The model of a medium for creation of electric hermetic screens of the radio electronic means. IJATCSE. 2019. 8(2). Pp. 300-304.

6. Iasechko M., Turinskyi O., Larin V., Prokopenko T., Kolmohorov O., Salash O., Tarshyn V. The Investigation of the Impulse Evolution of the Radio-Frequency and Optical Radiation During the Interaction With the Solid-State Plasma Media On Radioisotope and Hexaferrite Inclusions. IJETER. 2020. 8(4). Pp. 1333-1337.

DOI https://doi.org/10.30525/978-9934-588-79-2-1.41

RECOMMENDATIONS FOR SUBSTANTIATION OF REQUIREMENTS FOR CONSTRUCTION OF PROTECTION OF RADIOELECTRONIC MEANS FROM THE INFLUENCE OF POWERFUL ELECTROMAGNETIC RADIATION

\author{
Iasechko M. M. \\ Doctor of Technical Sciences, \\ Associate Professor at the Department \\ of Air Defense Armaments of the Land Forces \\ Ivan Kozhedub Kharkiv National Air Force University \\ Kharkiv, Ukraine \\ Liashenko V. \\ Candidate of Technical Sciences, \\ Senior Research Fellow \\ State Research Institute of Armament \\ and Military Equipment Testing and Certification, Ukraine \\ Chernihiv, Ukraine
}

